\title{
A STUDY ON CLINICO-ETIOLOGICAL PROFILE OF INFANTS PRESENTING WITH FIRST EPISODE OF SEIZURE IN TERTIARY CARE HOSPITAL
}

\author{
Akash Rai1, Sankar Kumar Das², Balai Chandra Karmakar ${ }^{3}$
}

${ }_{1}^{1}$ Postgraduate Trainee, Department of Paediatric Medicine, North Bengal Medical College and Hospital, Darjeeling, West Bengal, India. 2 Professor and HOD, Department of Paediatric Medicine, North Bengal Medical College and Hospital, Darjeeling, West Bengal, India. ${ }^{3}$ Associate Professor, Department of Paediatric Medicine, North Bengal Medical College and Hospital, Darjeeling, West Bengal, India.

\section{ABSTRACT}

\section{BACKGROUND}

Seizure is "a transient occurrence of signs and/or symptoms due to abnormal excessive or synchronous neuronal activity in the brain. The risk of seizures is the highest in the first year of life. Neonatal seizures have different causes and different risk factors depending on maturity, weight and underlying conditions. Children after the first four weeks of life are susceptible to metabolic derangements with mild illnesses, at an increased susceptibility for CNS infections and also at risk of seizures due to various agerelated syndromes e.g. febrile seizures, infantile spasm, Dravet syndrome etc. After the studies of Cheverie \& Acardi et al. not much work has been done on aetiology of seizures in this age group. There is a paucity of Indian data regarding the aetiology and outcome of seizures in infants after the neonatal period. Therefore, in this case control study with longitudinal design, we analysed the prevalence of various aetiologies, the clinical spectrum of seizure disorders and the primary outcome of infants aged 4 weeks to 12 months admitted with the first attack of acute seizure disorder. We wanted to determine the common aetiologies of the first episode of seizures among infants aged 4 weeks to 12 months admitted in North Bengal Medical College \& Hospital. We also wanted to determine the clinical sub-types of seizures and short-term ( 6 months) outcomes of the first episode of seizure among the study subjects.

\section{METHODS}

This is a hospital based observational study with longitudinal design, carried out (total 57 subjects) among infants admitted with first seizure, in the Dept. of Paediatrics, North Bengal Medical College \& Hospital, Darjeeling, West Bengal.

\section{RESULTS}

The study was conducted among 57 infants (Male-57.9\% and $42.1 \%$ females) to determine the common aetiologies and clinical sub types of first episode of seizure as well as the short-term (6 Months) outcome of first seizure in infants aged 4 weeks to 12 months. Among 57 study subjects, $29.8 \%$ belonged to $<6$ months age group followed by $70.2 \%$ in $\geq 6$ months age group and mean was 7.1 $( \pm 2.7)$ months. Present study revealed majority $(54.4 \%)$ of infants had provoked seizure, among them CNS infection (acute pyogenic bacterial meningitis, $21 \%$. Acute viral encephalitis and meningoencephalitis $(79 \%)$ are the most common $(33.3 \%)$ cause of seizure, followed by febrile seizure (14\%). Unprovoked seizure constituted $45.6 \%$ of cases in our study population. The most common seizure subcategories were generalized tonic (52.6\%) followed by generalized tonic clonic (14\%), focal clonic (14\%), generalized clonic $(8.7 \%)$, tonic clonic $(7 \%)$, and focal to bilateral tonic clonic (3.5\%). Current study has also shown 18 patients (32.1\%) developed subsequent seizure after first episode of seizure; among them $61.1 \%$ had developed within 24 hours of first seizure and $38.9 \%$ developed after 24 hours after first seizure.

\section{CONCLUSIONS}

CNS infection is most common cause of first seizure in this study, and also associated with high mortality rate. Early detection, timely referral to higher center, appropriate and timely management of these infants can prevent further progression of disease.

\section{KEY WORDS}

Infant, First Episode Seizure, Sub-Type, Outcome

HOW TO CITE THIS ARTICLE: Rai A, Das SK, Karmakar BC. A study on clinico- etiological profile of infants presenting with first episode of seizure in tertiary care hospital. J. Evolution Med. Dent. Sci. 2019;8(23):1852-1857, DOI: 10.14260/jemds/2019/407

\section{BACKGROUND}

Seizure is "a transient occurrence of signs and/or symptoms due to abnormal excessive or synchronous neuronal activity in the brain. ${ }^{1}$

It is one of the commonest childhood neurological illnesses occurring in 4-6 per 1000 children in the general population. ${ }^{2}$

'Financial or Other Competing Interest': None.

Submission 17-04-2019, Peer Review 25-05-2019,

Acceptance 01-06-2019, Published 10-06-2019.

Corresponding Author:

Dr. Balai Chandra Karmakar,

\#30H Harey Krista Sett Lane,

P. S. Sinthi, Kolkata-700050, West Bengal, India.

E-mail:balaikarmakar75@gmail.com

DOI: $10.14260 /$ jemds/2019/407

\section{(c) $\bigcirc)$}

$5-10 \%$ of children suffer at least one episode of seizure in the first 16 years of life. Seizures account for about $2 \%$ of all paediatric emergency department visits. ${ }^{3}$ The physician must know if a seizure occurred, whether it is the first episode or not, by taking the detailed history from the observer. ${ }^{4}$ Determining the type of seizure, and whether it constitutes part of a specific epilepsy syndrome, is important for purpose of work up, treatment and prognosis. The next goal is to determine the cause of seizure, which can be done by history and physical examination in the majority. In addition, other laboratory tests, EEGs and neuro-radiological examinations may be required.

An etiological classification of seizure disorders appropriate for epidemiological studies describes two broad groups- 


\section{Acute Symptomatic Seizure}

Also known as provoked seizure, is defined as a clinical seizure occurring at the time of a systemic insult or in close temporal association with a documented brain insult. Suggestions are made to define acute symptomatic seizures as those events occurring within 1 week of stroke, traumatic brain injury, anoxic encephalopathy, or intracranial surgery; at first identification of subdural hematoma; at the presence of an active central nervous system (CNS) infection; or during an active phase of multiple sclerosis or other autoimmune diseases. In addition, a diagnosis of acute symptomatic seizure should be made in the presence of severe metabolic derangements (Documented within $24 \mathrm{~h}$ by specific biochemical or hematologic abnormalities), drug or alcohol intoxication and withdrawal, or exposure to well-defined epileptogenic drugs. ${ }^{5}$ Acute symptomatic seizures are seizures closely related to neurological or systemic insults and represent about $40 \%$ of all first seizures. ${ }^{6}$

\section{Unprovoked Seizures}

Unprovoked seizure is defined as convulsive episodes occurring in the absence of a potentially responsible clinical condition or beyond the interval estimated for the occurrence of acute symptomatic seizures. The latter may be caused by a static injury (e.g., head trauma or stroke) and are referred to as remote symptomatic seizures or by a progressing injury (e.g., tumour or a degenerative disorder) and are referred to as progressive symptomatic seizures. They may occur in persons with no known insults to the brain and in the absence of an event generally considered to be a risk factor for epilepsy (Idiopathic or cryptogenic). Unprovoked seizures differ from acute symptomatic seizures in risk for seizure recurrence and mortality for several aetiologies. Unprovoked seizures may be single or recurrent. ${ }^{7}$ The risk of seizures is the highest in the first year of life. ${ }^{8}$ The neonatal seizures have different causes and different risk factors depending on maturity, weight and underlying conditions, plenty of data are available for the same including from India. ${ }^{9}$ Children after the first four weeks of life are susceptible to metabolic derangements with mild illnesses, at an increased susceptibility for CNS infections and also at risk of seizures due to various age related syndromes e.g. febrile seizures, infantile spasm, Dravet syndromes etc. After the seminal studies of Cheverie \& Acardi et al.10,11 not much work has been done on aetiology of seizures in this age group. There is a paucity of Indian data available regarding the aetiology and outcome of seizures in infants after the neonatal period.12,13

\section{METHODS}

\section{Settings and Design}

It is a hospital based observational study with longitudinal design, conducted in the Department of Paediatrics. North Bengal Medical College \& Hospital, Darjeeling, West Bengal ${ }^{14}$ Study was done by convenient sampling technique.

\section{Inclusion Criteria}

Infants between the 4 weeks to 12 months of age presenting with first episode of seizure.

\section{Exclusion Criteria}

Infants aged less than 4 weeks and more than 12 months of age, who had any significant perinatal history including neonatal seizure and infants with subsequent seizure and who had been evaluated before. Infants with significant chronic medical illness.

\section{Study Tools}

Structured proforma for evaluation of seizures divided in 4 sections.

\section{Section I}

Details of history like age, sex, family history, general and systemic examination, developmental status using Trivandrum developmental screening chart ${ }^{15}$, type of seizure, presence of associated illness etc.

\section{Section II}

Clinical profile of seizure: type of seizure ${ }^{16}$, duration of seizure, associated factors, medication require to control seizure.

\section{Section III}

All infants underwent essential investigations include routine blood count, blood Glucose, serum calcium, serum electrolytes, urea/creatinine ECG (QTc) within first 24 hour of admission. Additional investigations will be done as guided by history, physical examination and included blood culture, CSF examination, thyroid profile, EEG and CT/MRI brain.

\section{Section IV}

Short term follow-up of the patients up to 6 months at monthly interval after discharge regarding recurrence of seizure.

\section{Status Epilepticus}

Status epilepticus is a single epileptic seizure which lasts more than 30 minutes or a series of epileptic seizures in which function is not retrieved between ictal events for more than 30 minutes. ${ }^{17}$

\section{Febrile Seizure}

Simple febrile seizure is defined as a short ( $<15 \mathrm{~min})$ generalized seizure, not recurring within $24 \mathrm{~h}$ with no neurologic deficits and no previous afebrile seizures that occurs during a febrile illness not resulting from an acute disease of the nervous system and Complex febrile seizure is defined by focal, or generalized and prolonged seizure $(>15$ min), recurring more than once in 24 and/or associated with postictal neurologic abnormalities. ${ }^{18}$

\section{Statistical Analysis}

Data were organized and presented using the principles of descriptive and inferential statistics. Chi-square and Fisher's exact test were applied to test the significance, $\mathrm{p}$ value less than $0.05(\mathrm{p}<0.05)$ was considered as statistically significant. Analysis of the data was done by IBM SPSS version 20 . 

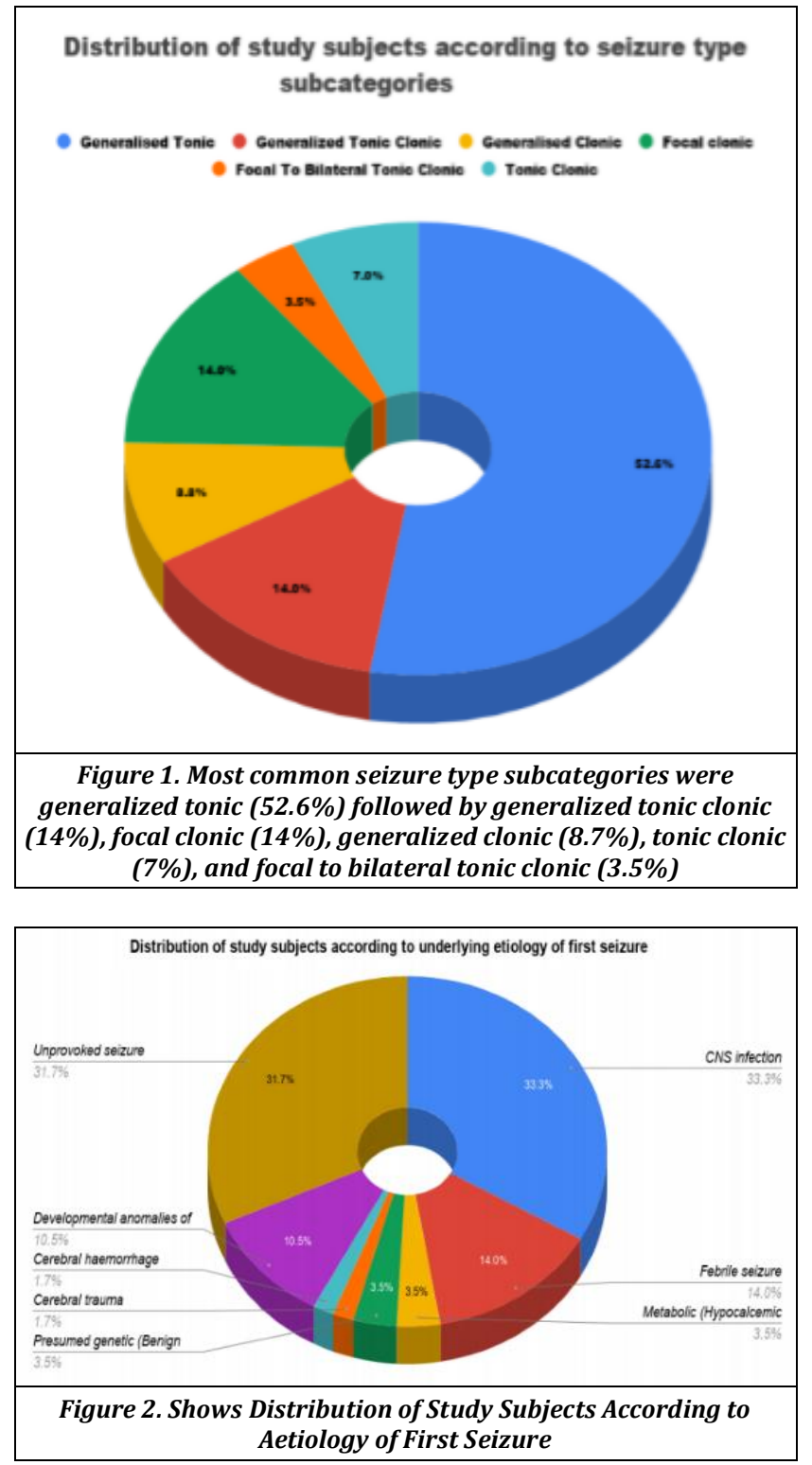

\begin{tabular}{|c|c|c|c|c|c|}
\hline \multirow{2}{*}{$\begin{array}{c}\text { Etiologic } \\
\text { Classification } \\
\text { of Seizure }\end{array}$} & \multicolumn{2}{|c|}{ Outcome } & \multirow[b]{2}{*}{ Total } & \multirow{2}{*}{$\begin{array}{l}\text { Chi square } \\
\text { (Fisher's } \\
\text { Exact Test) }\end{array}$} & \multirow[b]{2}{*}{$\mathbf{p}$} \\
\hline & $\begin{array}{l}\text { Died } \\
(\%)\end{array}$ & $\begin{array}{c}\text { Discharged } \\
(\%)\end{array}$ & & & \\
\hline \begin{tabular}{|l|} 
Provoked \\
\end{tabular} & $6(19.4)$ & 25 (80.6) & $31(100.0)$ & \multirow{3}{*}{2.74} & \multirow{3}{*}{0.02} \\
\hline Unprovoked & $0(0.0)$ & $26(100.0)$ & $26(100.0)$ & & \\
\hline Total & $6(10.5$ & $51(89.5)$ & $57(100.0$ & & \\
\hline
\end{tabular}

\section{RESULTS}

The study was conducted among 57 infants (male-57.9\% and $42.1 \%$ females) to find out the common aetiologies and clinical sub types of first episode of seizure, of which $29.8 \%$ belonged to $<6$ months and $70.2 \%$ in $\geq 6$ months of age with mean age was $7.1( \pm 2.7)$ months. Majority $91.2 \%$ were term neonates and $8.8 \%$ were preterm neonates and $77.2 \%$ were born by NVD and $22.8 \%$ were born by LSCS. $10.5 \%$ had developmental delay and $89.5 \%$ had no delay in development. Mean Weight $(\mathrm{kg})$ Length $(\mathrm{cm})$ Head circumference $(\mathrm{cm})$ was $6.6(\mathrm{SD} \pm 1.2), 64.3$ (SD \pm 5.6$), 41.3$ ( $\mathrm{SD} \pm 2.2$ ) respectively. Family history of seizure was absent in $52(91.2 \%)$ of study subjects and $4(7 \%)$ had history of seizure disorder in siblings and $1(1.8 \%)$ had history of simple febrile seizure in sibling. $98.2 \%$ had no significant past history.
27(47.4\%) cases seizure was solitary followed by twice (38.6\%) and multiple (14\%) episode and $5.3 \%$ subjects developed status epilepticus. 12 (21.1\%) of the study subjects received treatment with Phenobarbitone(66.6\%), Phenytoin (16.7\%), and both Phenobarbitone and Phenytoin (16.7\%) before admission at primary or secondary health centre and $78.9 \%$ did not receive any treatment. Seizure persisted less than 15 minute $48(84.2 \%$ ) cases while 9 (15.8 \%) cases were more than 15 minutes. Most common post ictal symptom was drowsiness (61.4\%), followed by altered sensorium (31.6\%), and lethargy (7\%). Etiological factors like fever (50.8\%) fever, poor feeding (3.5\%) were positive in 31 subjects. 18 patients developed subsequent seizure, 11 (61.1 \%) developed it within 24 hours after first seizure and 7(38.9 $\%)$ developed after 24 hours of first seizure, of which 8( $44.4 \%$ ) had multiple episodes followed by single episode 7 (38.9\%), two episodes 3 (16.7\%). Among 18 patients who developed subsequent seizure, majority of them had generalized seizure pattern $16(88.9 \%)$, followed by 2 ( 11.1 $\%$ ) focal. 25 ( $43.8 \%$ ) cases seizure are controlled by single antiepileptic drugs, $14(24.5 \%)$ did not required any antiepileptic drugs, $12(21.1 \%)$ required 2 antiepileptic drugs, 5 (8.8\%) required 3 antiepileptic drugs and 1( $1.8 \%$ ) required 4 antiepileptic drugs.

Mean blood glucose $(\mathrm{mg} / \mathrm{dl})$, Serum Calcium $(\mathrm{mg} / \mathrm{dl})$, Haemoglobin (gm/dl), Total leukocyte counts $\left(\mathrm{mm}^{3}\right)$, and Platelets (lakh) was 104.1 (SD \pm 26.3 ), 8.6 (SD \pm .71 ), 10.0 (SD \pm 1.3 ), 9528.0 (SD \pm 3686.2 ), 2.50 (SD \pm \pm .72 ) respectively. Thyroid function was found to be within normal limit. Serum electrolytes were within normal limits except one had hyponatremia and one both hyponatremia and hyperkalaemia and two had abnormal renal function test. $10.5 \%$ had positive CRP value and, $48.6 \%$ had normal CSF reports (CSF done in 20 patients), $40.5 \%$ patents showed viral infection, $10.8 \%$ showed bacterial infection. Blood culture was positive blood culture for Klebsiella pneumonia only one patient among 35 study subjects (Culture done in 22 patients). $46.4 \%$ had normal EEG, $53.6 \%$ had abnormal EEG of which $36.5 \%$ had generalized abnormalities and $17.1 \%$ had focal abnormalities (EEG done in 10 patients). Among 24 study subjects (MRI done in 10 patients) who had abnormal MRI brain, $50 \%$ had acute meningoencephalitis, $12.5 \%$ showed acute viral encephalitis, $8.3 \%$ showed intra cranial bleeding, $4.1 \%$ showed acute leptomeningitis with subdural effusion and rest $24 \%$ showed others type of brain abnormality like Included Agenesis of corpus callosum, Colpocephaly with mega cisterna magna, Colpocephaly, Lissencephaly, Porencephalic cyst in right cerebral hemisphere, Schizencephaly. ECG (QTc) was normal among all 57 cases. Underlying aetiology of first seizure was CNS infection (33.3\%) followed by unprovoked seizure in $31.7 \%$, febrile seizure in $14 \%$.

Developmental anomalies of cerebral Structure in 10.5\%, Hypocalcaemic seizure in $3.5 \%$, Benign infantile seizure in $3.5 \%$, cerebral trauma $1.7 \%$, Cerebral haemorrhage $1.7 \%$. Developmental anomalies of cerebral structure like Colpocephaly with mega cisterna magna, Colpocephaly, Lissencephaly, Porencephalic cyst, Agenesis of corpus callosum, Schizencephaly were found 6 cases (One each).

6 patients died during hospital stay, so follow up hah done in total 51 study subjects of which 13 (25.5\%) subjects 
developed recurrence of seizure and 38 ( $74.5 \%$ ) had no seizure and majority of recurrence occurred either 5 months or 6 months after discharge.

Table 1 shows (Fisher's Exact Test was applied as 2 cells $(50.0 \%)$ have expected count less than 5 . The minimum expected count is $2.74, \mathrm{df}=1, \mathrm{p}=.02$ ) proportion of death was higher among provoked group $6(19.4 \%)$ compared to unprovoked group nil $(0.0 \%)$ and the distribution was found to be statistically significant $(\mathrm{p}=.02)$.

We found both provoked (31) and unprovoked (26) seizures and proportion of death was higher among provoked group 6 (19.4\%) compared to unprovoked group (nil death, $\mathrm{p}=.02$ ). Recurrence of seizure among 51 patients ( 6 expired) was higher among unprovoked group 9 (34.6\%) compared to provoked group $4(16 \%)$ and the distribution was not found to be statistically significant; $p=0.12$. Similarly recurrence of seizure was higher $3(50.0 \%)$ among the developmentally delayed children compared to the subjects who did not have delay $10(22.2 \%)$ and was not found to be statistically significant; $\mathrm{p}=0.16$ but recurrence was higher with EEG abnormality compared to the individuals who had no EEG abnormality (50.0\% vs $4.8 \%$ ) and statistically significant ( $p=0.001$ ).Recurrence of seizure was $27.7 \%$ in abnormal MRI and $26 \%$ in normal MRI (Statistically not significant).

\section{DISCUSSION}

Seizure is "a transient occurrence of signs and/or symptoms due to abnormal excessive or synchronous neuronal activity in the brain. ${ }^{1}$ It is one of the commonest childhood neurological illnesses occurring in 4-6 per 1000 children in the general population. ${ }^{2}$

Current study showed $29.8 \%$ less than 6 months of age and $70.2 \%$ were $\geq 6$ months of age with mean age was 7.1 $\pm 2.7)$ months which was similarly to another study conducted by Qadri I et al ${ }^{19}$ among patients presenting as first seizure after neonatal age reported mean age at seizure occurrence was 5.3 months (S.D. \pm 2.1 ) with maximum age at presentation of 12 months and minimum of 1.5 months. Male preponderance was found (male $57.9 \%$ and female $42.1 \%$ ) correspond to Qadri I et al. ${ }^{19}$ and Nikunj et al. ${ }^{20}$ study. The study also showed that $10.5 \%$ of the infants had developmental delay and $89.5 \%$ infants found without any developmental delay. Current study revealed $47.4 \%$ infants presented with solitary episode of seizure whereas $38.6 \%$ infants had double episode and $14 \%$ infants had multiple episode of seizure on admission similar to study done by Nikunj et al. ${ }^{20}$ Present study revealed that the most common seizure type was generalized seizure $(75.4 \%)$ followed by focal (17.5\%) and unknown types (7.1\%), like Adhikari et al,21 Nikunj et al,20 Qadri I et al,19 Idro $R$ et al ${ }^{22}$ and Chen CY et al,23 Ahmed et al.24 studies. Only $5.3 \%$ study subjects develop status epilepticus in our study and in a similar study conducted by Singh RD et al. ${ }^{25}$ reported $8 \%$ patient and Qadri et al. ${ }^{19}$ reported $4 \%$ patients. We found fever as one of the common associated symptoms (50.8\%) with seizure. Poor feeding was also seen in $3.5 \%$ cases whereas $45.7 \%$ children presented with only seizure without any associated symptoms similar to Chaudhary $\mathrm{N}$ et al. ${ }^{26}$ reported loss of consciousness (55.4\%), fever (39.9\%), vomiting (35.1\%) and headache $(16.1 \%)$ as four leading clinical complaints in admitted seizure patients. Seizures coexisted with fever in $53.5 \%$ of cases was also reported by Adhikari et al.21
There are many possible aetiologies of a first seizure attack in children, including infection, neurologic/ developmental causes, traumatic head injury, toxins, and metabolic disturbances. ${ }^{22,23,27,28}$

Present study revealed majority of ( $54.4 \%$ ) of infants had provoked seizure, among them CNS infection (Acute pyogenic bacterial meningitis, $21 \%$ and Acute Viral encephalitis and meningoencephalitis, 79\%) are the most common $(33.3 \%)$ cause of seizure, followed by febrile seizure (14\%).Unprovoked seizure constituted $45.6 \%$ of case in our study population. Gogoi A et al. ${ }^{29}$ Martindale JL et al. ${ }^{3}$ Taherian et al. ${ }^{30}$ and Hauser WA et al. ${ }^{31}$ Smith et al. ${ }^{32}$ were reported febrile seizures as one of the most common causes of seizure attack in children, because of inclusion of later age group. A study conducted by Nikunj et al.20 in same age group revealed majority $(68 \%)$ of the infants had provoked seizures, mainly due to hypocalcaemia and neuro-infections, which is similar to our study, however in our case CNS infection is more common cause of provoked seizure. A study conducted by Huang et al. ${ }^{33}$ also revealed that leading cause of seizure is neuro-infection in particular age group. Current study has also shown 18 patients (32.1\%) developed subsequent seizure after first episode of seizure, among them $61.1 \%$ had developed within 24 hours after first seizure and $38.9 \%$ developed after 24 hours after first seizure. In this study $89.5 \%$ of the study subjects who presented with seizure were discharged after successful treatment, but $10.5 \%$ patients died in hospital during treatment. All death is due to CNS infection. A study by Nikunj et al. ${ }^{20}$ revealed $12 \%$ infants died during the course of the study, most of them died during hospital stay, maximum seizure deaths were noticed in the neuro-infection group, which is similar finding in our study. The study further confirmed that provoked seizure had significantly worst prognosis (Death) than unprovoked seizure $(\mathrm{p}<0.05)$ similar to study conducted by Loiseau J et al. ${ }^{34}$ Recent study has revealed that $25.5 \%$ of the study subjects had recurrent seizure. All the recurrence occurred within 6 months of first episode of seizure. This study further confirmed that patients with EEG abnormality had significant chance of recurrence, though recurrence was higher among patients with developmental delay and Unprovoked seizure, but these were not statistically significant $(p>0.05)$ comparable to study conducted by Cavazzuti et al. ${ }^{35}$ Shinnar et al. ${ }^{36}$ Krammer et al. ${ }^{37}$

\section{Limitations of The Study}

This study was done in small sample size ( $n=57)$ with up to 6 months follow up period so we might miss some delayed occurrence of seizure. An unavailability of video EEG, ictal EEG, and seizure semiology confirmation is lacking in this study. The details of other causes contributing for seizures like inborn error of metabolism could not be specified due lack of investigations.

\section{CONCLUSIONS}

Most common seizure onset type was generalized, followed by focal and unknown onset. Subcategories were- generalized tonic followed by generalized tonic clonic, focal clonic. Provoked causes mainly CNS infections like acute viral encephalitis and meningoencephalitis were the major aetiology followed by unprovoked causes among infants presenting with 1st seizure. One fourth of the study subjects 
had recurrence of seizure during follow up and occurred within 5-6 months after discharge. Mortality was significantly associated with seizure aetiology with higher death among provoked aetiology, because of CNS infection compared to unprovoked group. Recurrence of the seizure was associated with EEG abnormality, which is statistically significant.

\section{Ethical Consideration}

The study was approved by of North Bengal Medical College \& Hospital, Darjeeling, West Bengal Ethical Committee. Written consent was taken from parents of the involved neonates.

\section{REFERENCES}

[1] Fisher RS, Van Boas EW, Blume W, et al. Epileptic seizures and epilepsy: definitions proposed by the International League Against Epilepsy(ILAE) and The International Bureau for Epilepsy (IBE). Epilepsia 2005;46(4):470-2.

[2] Cowan L, Bodensteiner J, Leviton A, et al. Prevalence of epilepsies in children and adolescent. Epilepsia 1989;30(1):94-106.

[3] Martindale JL, Goldstein JN, Pallin DJ. Emergency department seizure epidemiology. Emerg Med Clin North Am 2011;29(1):15-27.

[4] Hirtz D, Ashwal S, Berg A, et al. Practice parameter: evaluating a first non-febrile seizure in children: report of the quality standards subcommittee of the American Academy of Neurology, The Child Neurology Society, and The American Epilepsy Society. Neurology 2000;55(5):616-23.

[5] Beghi E, Carpio A, Forsgren L, et al. Recommendation for a definition of acute symptomatic seizure. Epilepsia 2010;51(4):671-5.

[6] Beleza P. Acute symptomatic seizures: a clinically oriented review. Neurologist 2012;18(3):109-19.

[7] Hauser WA, Beghi E. First seizure definitions and worldwide incidence and mortality. Epilepsia 2008; Suppl 49:8-12.

[8] Ellenberg JH, Hirtz DG, Nelson KB. Age of onset of first seizure in young children. Annals of Neurology 1984;15(2):127-34.

[9] Kumar A, Gupta A, Talukdar B. Clinic-etiological and EEG profile of neonatal seizures. Indian J Pediatr 2007;74(1):33-7.

[10] Chevrie JJ, Aicardi J. Convulsive disorders in the first year of life: etiologic factors. Epilepsia 1977;18(4):489-98.

[11] Chevrie JJ, Aicardi J. Convulsive disorders in the first year of life: neurological and mental outcome and mortality. Epilepsia 1978;19(1):67-74.

[12] Udani V. Pediatric epilepsy - an Indian perspective. The Indian Journal of Pediatrics 2005;72(4):309-13.

[13] Amudhan S, Gururaj G, Satishchandra P. Epilepsy in India I: epidemiology and public health. Annals of Indian Academy of Neurology 2015;18(3):263-77. (Date accessed: 4th April 2016).

[14] Report on comparative backwardness of north Bengal region. Last assessed on 21st October, 2018. http://www.planningcommission.nic.in/reports/sere port/ser/stdy_bkwardnb.pdf.
[15] Nair MKC, George B, Philip E, et al. Trivandrum developmental screening chart. Indian Pediatr 1991;28(8):869-72.

[16] Fisher RS, Cross JH, D'Souza C, et al. Instruction manual for the ILAE 2017 operational classification of seizure types. Epilepsia 2017;58(4):531-42.

[17] Commission on Epidemiology and Prognosis. International League Against Epilepsy. Guideline for epidemiologic studies on epilepsy. Epilepsia 1993;34(4):592-6.

[18] Capovilla G, Mastrangelo M, Romeo A, et al. Recommendations for the management of "febrile seizures" Ad hoc Task Force of LICE Guidelines Commission. Epilepsia 2009;50 Suppl 1:2-6.

[19] Qadri I, Bhat MS, Hussain WS, et al. Profile of first time seizure in infants with 1 to 12 months of age presenting to a tertiary care pediatric hospital. J Pediatr Neurol Disord 2017;3:110. Doi:10.4172/25725203.1000110

[20] Nikunj NK, Mishra D, Juneja M, et al. Etiology and short-term outcome of first seizure in hospitalized infants. Indian Pediatr 2016;53(10):924-6.

[21] Adhikari S, Sathian B, Koirala DP, et al. Profile of children admitted with seizures in a tertiary care hospital of Western Nepal. BMC Pediatrics 2013;13:43.

[22] Idro $R$, Gwer $S$, Kahindi $M$, et al. The incidence, aetiology and outcome of acute seizures in children admitted to a rural Kenyan district hospital. BMC Pediatr 2008;8:5.

[23] Chen CY, Chang YJ, Wu HP. New-onset seizures in pediatric emergency. Pediatr Neonatol 2010;51(2):103-11.

[24] Ahmed S, Alam ST, Rahman MM, et al. Clinical profile of early childhood epilepsy: a cross sectional study in a tertiary care hospital. Mymensingh Med J 2016;25(1):96-101.

[25] Singh RD, Suryavanshi S. A hospital based study on clinicoetiological profile of seizures in children - a Kanpur (U.P. India) experience. IJCMR 2016;3(10):3003-7.

[26] Chaudhary N, Gupta MM, Shrestha S, et al. Clinicodemographic profile of children with seizures in a tertiary care hospital: a cross-sectional observational study. Neurology Research International 2017;2017:1524548. https://doi.org/10.1155/2017/1524548.

[27] Murthy JM, Yangala R. Acute symptomatic seizures incidence and etiological spectrum: a hospital-based study from South India. Seizure 1999;8(3):162-5.

[28] Mehrotra P, Marwaha RK, Aneja S, et al. Hypovitaminosis D and hypocalcemic seizures in infancy. Indian Pediatr 2010;47(7):581-6.

[29] Gogoi A, Islam AKS, Panyang R, et al. A prospective hospital based study on the clinico-etiological profile of first episode seizures in children. Int J Med Res Prof 2016;2(3):108-14.

[30] Reza T, Mohammad FB, Alireza R, et al. The etiologic profile of the pediatric seizure: an epidemiological study from Iran. ICNSJ 2017;4(3):98-102.

[31] Hauser WA. The prevalence and incidence of convulsive disorders in children. Epilepsia 1994;35 Suppl 2:S1-S6. 


\section{Jemds.com}

[32] Smith RA, Martland T, Lowry MF. Children with seizure presenting to accident and emergency. J Accid Emerg Med 1996;13(1):54-8.

[33] Huang CC, Chang YC, Wang ST. Acute symptomatic seizure disorders in young children - a population study in southern Taiwan. Epilepsia 1998;39(9):9604.

[34] Loiseau J, Picot MC, Loiseau P. Short-term mortality after a first epileptic seizure: a population-based study. Epilepsia 1999;40(10):1388-92.

\section{Original Research Article}

[35] Cavazzuti GB, Ferrari P, Lalla M. Follow up study of 482 cases with convulsive disorders in the first year of life. Dev Med Child Neurol 1984;26(4):425-37.

[36] Shinnar S, Berg AT, Moshe SL, et al. The risk of seizure recurrence after a first unprovoked afebrile seizure in childhood: an extended follow-up. Pediatrics 1996;98(2 Pt 1):216-25.

[37] Kramer U, Phatal A, Neufeld MY, et al. Outcome of seizures in the first year of life. European Journal of Paediatric Neurology 1997;1(5-6):165-71. 